\title{
Construction of Dopamine-Releasing Gold Surfaces Mimicking Presynaptic Membrane by On-Chip Electrochemistry
}

Jun Li,,${ }^{+\ddagger}$ Chun-Lin Sun,${ }^{\S} \ddagger$ Pengrong An,${ }^{+}$Xiaoyan Liu,,${ }^{\perp}$ Ruihua Dong,,${ }^{\perp}$ Jinghong Sun, ${ }^{+}$ Xingyu Zhang, ${ }^{\dagger}$ Yanbo Xie, ${ }^{+}$Chuanguang Qin, ${ }^{+}$Wenfu Zheng, ${ }^{* \perp}$ Hao-Li Zhang, ${ }^{\star \S}$ Xingyu Jiang $^{* / / \perp}$

${ }^{+}$MOE Key Laboratory of Space Applied Physics and Chemistry, Joint Lab of Nanofluidics and Interfaces (LONI), School of Natural and Applied Sciences, Northwestern Polytechnical University, Xi'an, Shanxi 710072, P. R. China

"Department of Biomedical Engineering, Southern University of Science and Technology, No. 1088 Xueyuan Rd, Nanshan District, Shenzhen, Guangdong 518055, P. R. China

${ }^{\perp}$ CAS Center for Excellence in Nanoscience, CAS Key Lab for Biological Effects of Nanomaterials and Nanosafety, National Center for NanoScience and Technology, Beijing 100190, P. R. China

${ }^{\circledR}$ State Key Laboratory of Applied Organic Chemistry (SKLAOC), College of Chemistry and Chemical Engineering, Lanzhou University, Lanzhou, Gansu 730000, P. R. China

\section{Table of Content}

1. Experimental Section

2. Experimental Results 


\section{Experimental Section}

Materials: All analytical grade reagents were purchased from J\&K Chemical Co., Ltd, China. The solvents were purified by the standard procedures.

Computational details: The geometry optimization and Raman spectra simulation of the different structures were calculated by using the Density Functional Theory (DFT) with B3LYP method, using the basis set of $6-311++G(d, p)$. All quantum chemistry calculations were performed by Guassian09.

Scanning electron microscopy combined with energy dispersive spectroscopy (SEM-EDS) Measurements: The SEM-EDS measurements were performed with a Hitachi SU8200 instrument. The samples for SEM-EDS measurements were bare gold-coated silicon slides or p-DA SAMs on gold-coated silicon slides $(5 \mathrm{~mm} \times 5 \mathrm{~mm}$ size $)$. The elements which were taken into account for the analysis were $\mathrm{C}, \mathrm{O}, \mathrm{N}$, and $\mathrm{Au}$.

Ellipsometry: A commercially available imaging ellipsometry (EP3, Nanofilm Technologie, Germany) was used to determine the thicknesses of the monolayers on gold substrate. The measurements were taken using a $532 \mathrm{~nm} 20 \mathrm{~mW}$ solid state laser source. The light incident angle was $70^{\circ}$ to the surface normal. The organic phase of the monolayers was assumed to be isotropic with a refractive index $n$ equal to 1.5 .

Membrane potential assay: FluoVolt ${ }^{\mathrm{ma}}$ membrane potential kit (Invitrogen) was used to perform the membrane potential measurements. Rat hippocampal neurons were rinsed with Live Cell Imaging Solution (LCIS) and treated with FluoVolt ${ }^{\mathrm{rx}}$ membrane potential kit mixed with $20 \mathrm{mM}$ glucose stock in LCIS, then the cells were incubated at room temperature for 15-30 min. We removed FluoVolt ${ }^{\mathrm{nt}}$ loading solution, and washed the cells twice in LCIS. We add $2 \mathrm{ml}$ of $20 \mathrm{mM}$ glucose stock solution in LCIS. Time-lapse fluorescence images were captured on a confocal microscope (Zeiss LSM 710). A potential of $-1.0 \mathrm{~V}$ was applied on the gold surface for $300 \mathrm{~s}$.

Cytotoxicity test: The cytotoxicity of DA SAMs was assessed by staining cells using a Live/Dead kit (Biovision). Hippocampal neurons were cultured on a DA SAMs-coated gold 
surface in a 12-well microplate (approximately 100,000 cells per well). After culturing for a week, a Calcein AM and Propidium Iodide (PI) PBS solution was added and cultured for another $30 \mathrm{~min}$ in normal culture environment. We determined the cell viability by using a confocal microscope (Carl Zeiss LSM710) whereby we calculated viability by counting live (green) and dead (red) cells, and expressed them as percentages.

\section{Experimental Results}
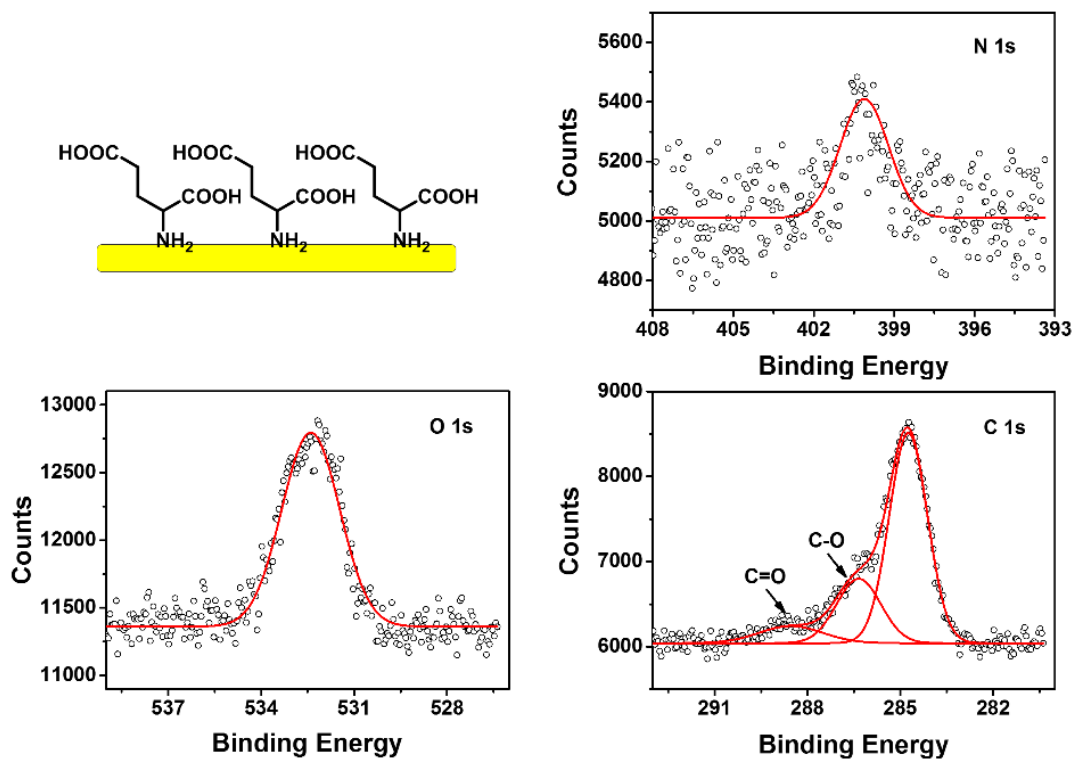

Figure S1. The XPS spectra of glutamic acid on gold surface.

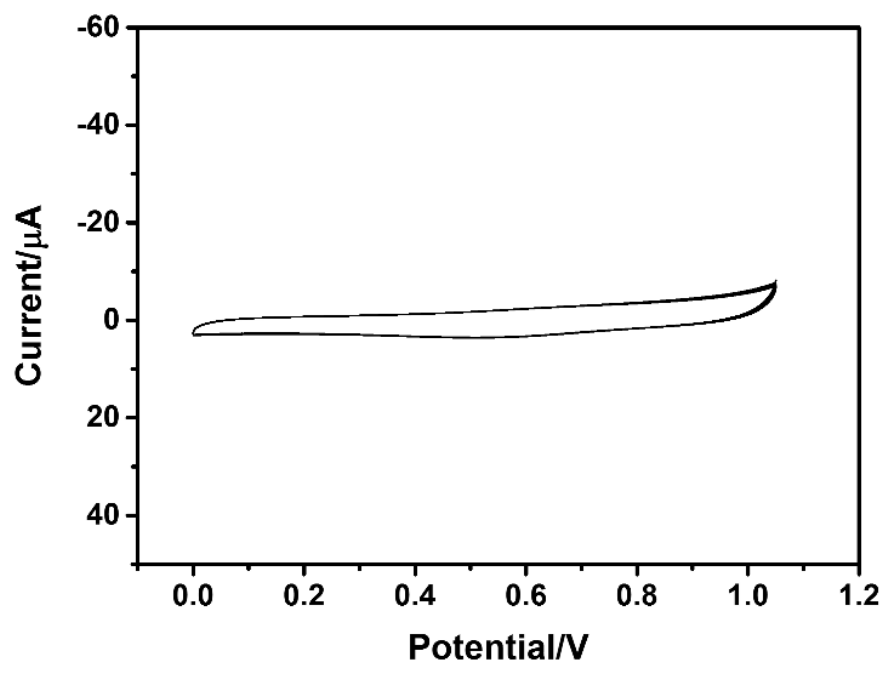

Figure S2. Consecutive CVs of bare gold electrode in $0.5 \mathrm{M} \mathrm{H}_{2} \mathrm{SO}_{4}$. Scan number $=10$. 


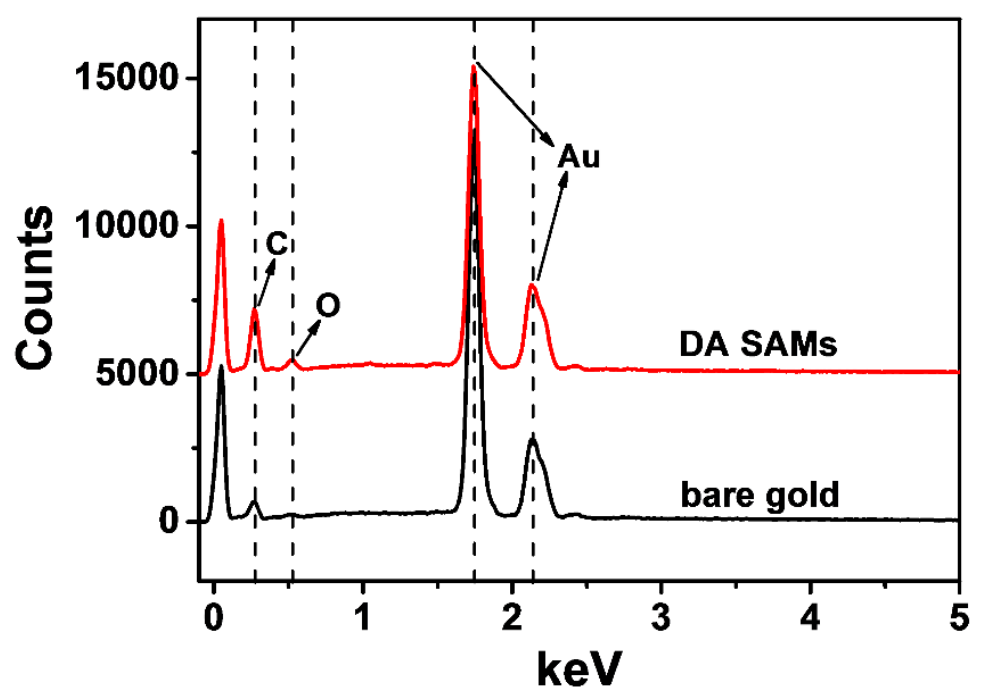

Figure S3. Representative SEM-EDS spectra collected on the bare gold and DA SAMs surfaces, respectively. The $\mathrm{C}$ and $\mathrm{O}$ peaks of the DA SAMs surface both increased compared with the spectrum recorded on bare gold surface, indicating the presence of DA SAMs on gold surface after mobilization.

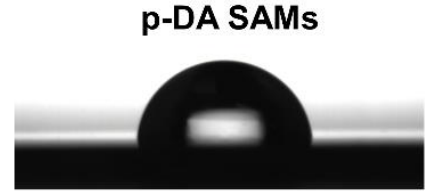

$79.5^{\circ}$

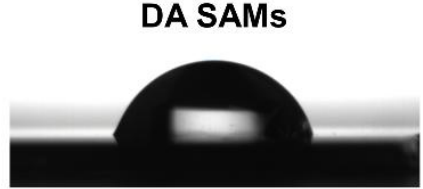

$74.7^{\circ}$

Figure S4. Contact angles of p-DA SAMs and DA SAMs. The contact angle of water drop on p-DA SAMs surface is slightly larger than that on the DA SAMs surface. This may be assigned to the change of methoxyl groups to hydroxyl groups.

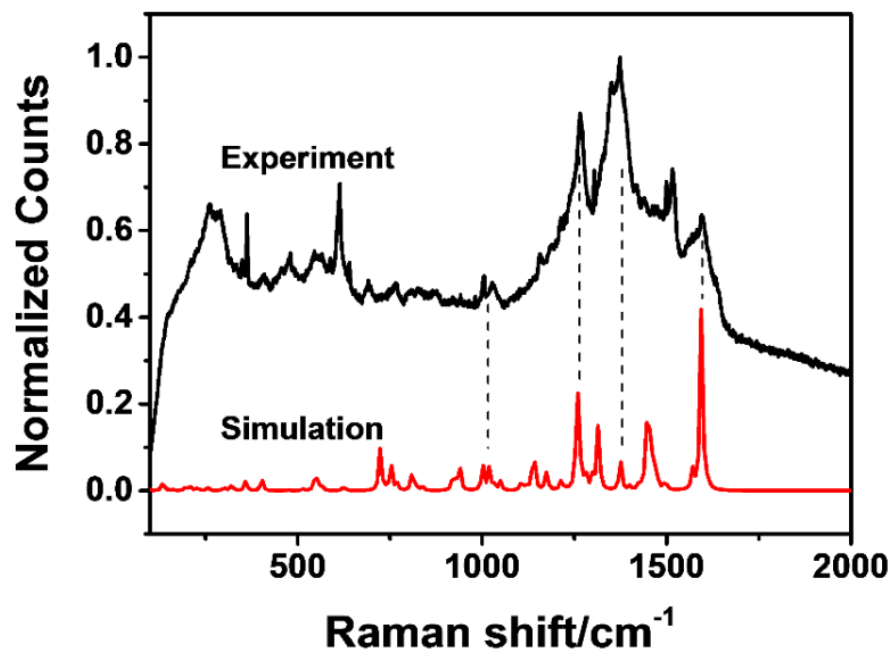

Figure S5. The SERS spectrum of the p-DA SAMs and simulated Raman spectrum of p-DA molecule. 


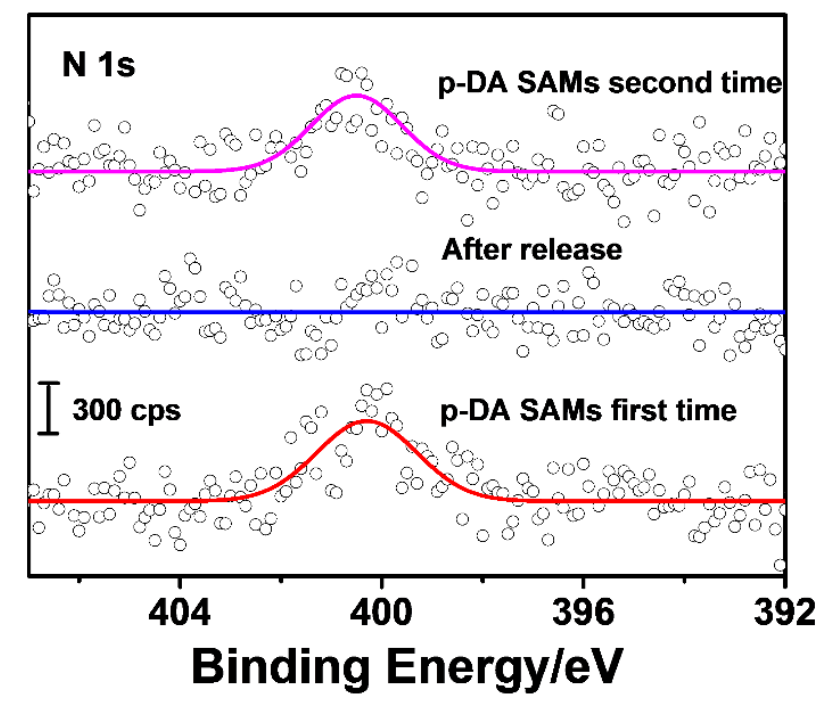

Figure S6. XPS characterization of gold surface: formation of the p-DA SAMs for the first time (red line); after electrochemical release of p-DA SAMs (blue line); formation of the p-DA SAMs for the second time (purple line). We first constructed p-DA SAMs on gold surface. The $\mathrm{N} 1$ s peak at $400.3 \mathrm{eV}$ indicates the formation of amine-Au bond (red line). After that, a negative potential of - $0.85 \mathrm{~V}$ (vs. SCE) was applied on the gold surface for $80 \mathrm{~s}$ to release the p-DA SAMs. There was no obvious peak in the XPS spectrum after electrochemical release, suggesting the cleavage of amine-Au bond (blue line). Then, p-DA SAMs was constructed on the same gold surface for the second time. A N 1s peak at $400.5 \mathrm{eV}$ emerged again, implying the formation of amine-Au bond for the second time (purple line). These results confirm that the formation of amine-Au bond is reversible.

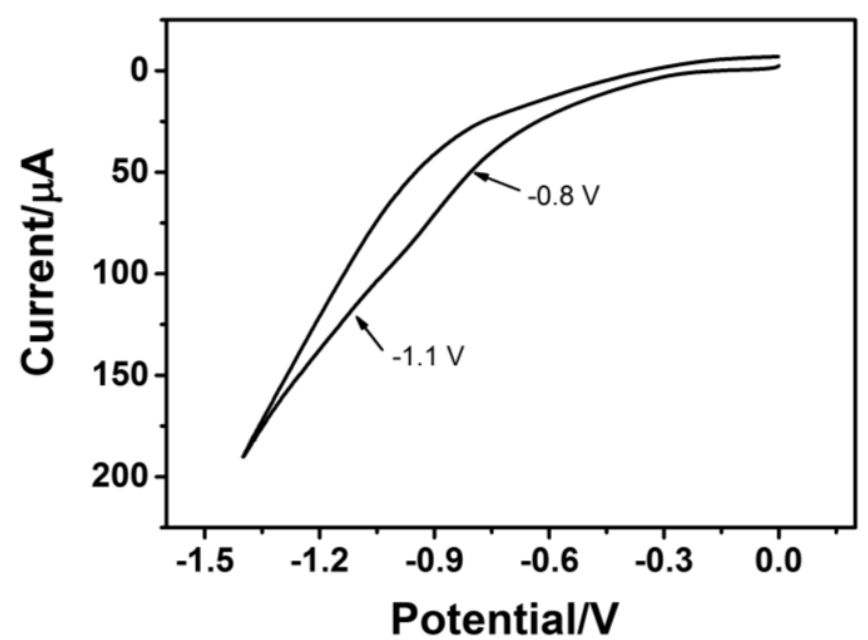

Figure S7. Cyclic voltammogram of the DA SAMs in PBS $(\mathrm{pH}=7.4)$ after reaction with CRGDK-FITC peptide. 


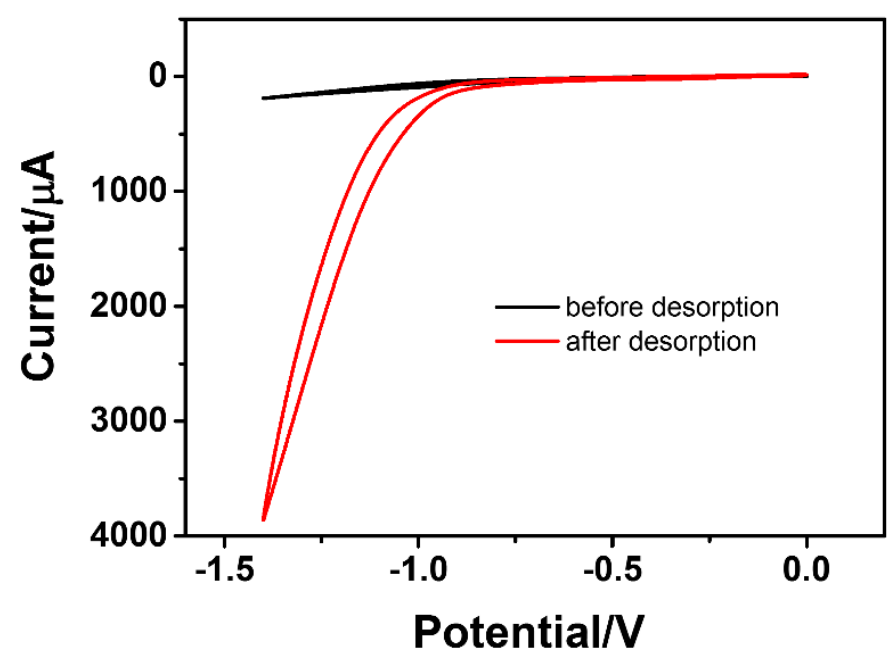

Figure S8. CVs of the DA SAMs after reaction with CRGDK-FITC peptide in PBS ( $\mathrm{pH}=7.4)$ before (black line) and after (red line) the application of a negative potential (-1.3 V for $100 \mathrm{~s})$.

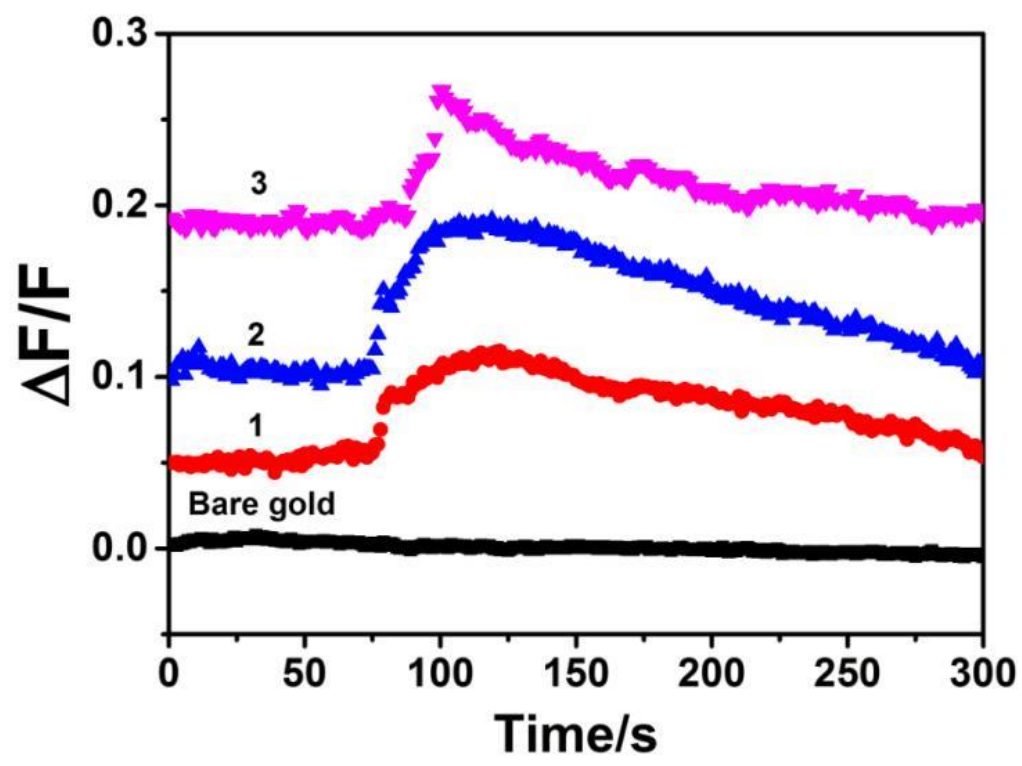

Figure S9. The variations of neural membrane potential were captured after application of $-1.0 \mathrm{~V}$ on the DA SAMs-releasing gold surface on which hippocampal neurons attached. The neurons were stained by FluoVolt (Invitrogen ${ }^{\mathrm{rm}}$ ) before imaging. A series of fluorescent images were captured at different time 
points and the relative changes in FluoVolt emission versus time were plotted. The red, blue, and pink lines represent the variation trends of membrane potential recorded from three different neurons on DA SAMs, respectively. Neurons on bare gold surface stained by FluoVolt and under the same electrochemical condition were set as a control (black line).
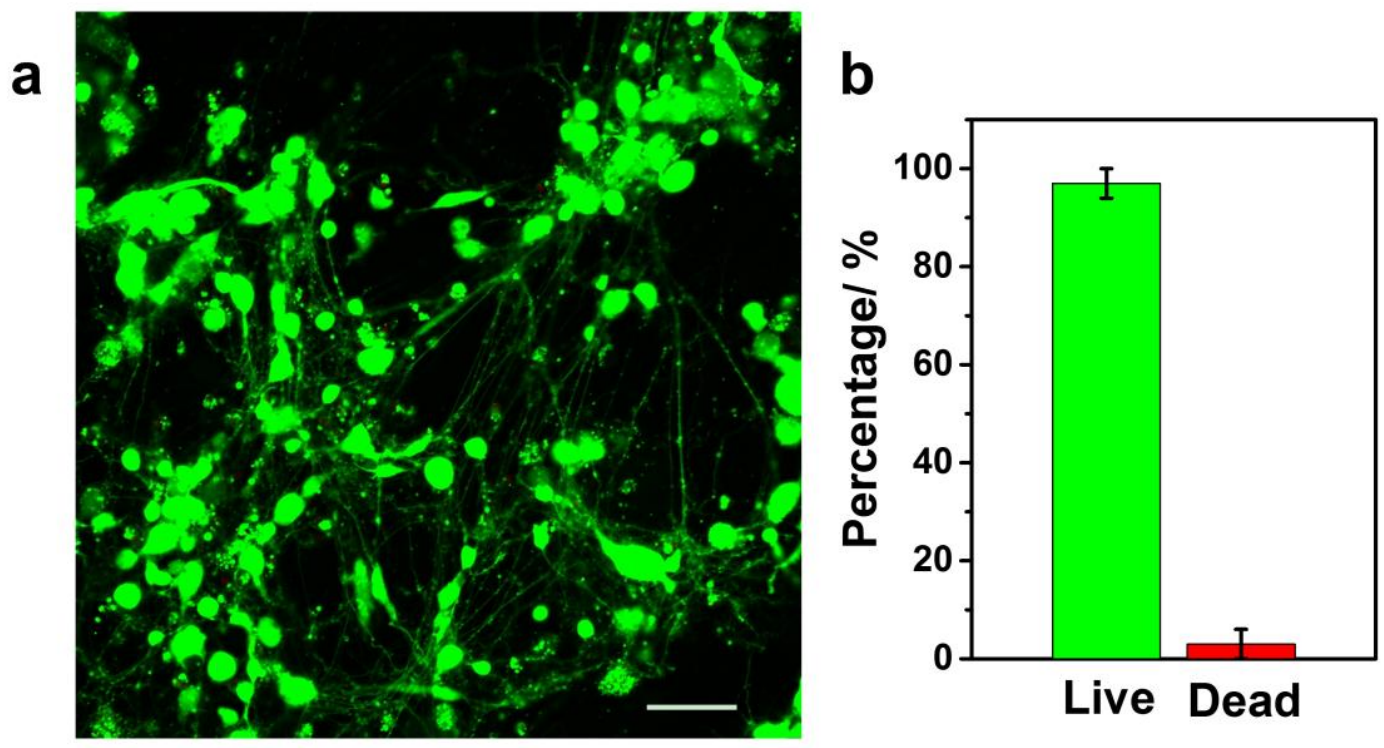

Figure S10. Cytotoxicity assay of the DA SAMs on gold surface. a) Confocal image of the hippocampal neuron stained with a Live/Dead kit after culturing for 1 week on DA SAMs. The scale bar is $100 \mu \mathrm{m} . \mathrm{b}$ ) The statistical data of the viability of the neurons on DA SAMs.

\section{References:}

(1) Frisch, M. J.; Trucks, G. W.; Schlegel, H. B.; Scuseria, G. E.; Robb, M. A.; Cheeseman, J. R.; Montgomery, J. A., Jr.; ; Vreven, T.; Kudin, K. N.; Burant, J. C.; Millam, J. M.; Iyengar, S. S.; Tomasi, J.; Barone, V.; Mennucci, B.; Cossi, M.; Scalmani, G.; Rega, N.; Petersson, G. A.; Nakatsuji, H.; Hada, M.; Ehara, M.; Toyota, K.; Fukuda, R.; Hasegawa, J.; Ishida, M.; Nakajima, T.; Honda, Y.; Kitao, O.; Nakai, H.; Klene, M.; Li, X.; Knox, J. E.; Hratchian, H. P.; Cross, J. B.; Bakken, V.; Adamo, C.; Jaramillo, J.; Gomperts, R.; Stratmann, R. E.; Yazyev, O.; Austin, A. J.; Cammi, R.; Pomelli, C.; Ochterski, J. W.; Ayala, P. Y.; Morokuma, K.; Voth, G. A.; Salvador, P.; Dannenberg, J. J.; Zakrzewski, V. G.; Dapprich, S.; Daniels, A. D.; Strain, M. C.; Farkas, O.; Malick, D. K.; Rabuck, A. D.; Raghavachari, K.; Foresman, J. B.; Ortiz, J. V.; Cui, Q.; Baboul, A. G.; Clifford, S.; Cioslowski, J.; Stefanov, B. B.; Liu, G.; Liashenko, A.; Piskorz, P.; Komaromi, I.; Martin, R. L.; Fox, D. J.; Keith, T.; Al-Laham, M. A.; Peng, C. Y.; Nanayakkara, A.; Challacombe, M.; Gill, P. M. W.; Johnson, B.; Chen, W.; Wong, M. W.; Gonzalez, C.; Pople, J. A. Gaussian 09, Revision A. 01 2009, Gaussian, Inc.: Wallingford, CT, 2004. 